\title{
Inovações Desenvolvidas em Universidades - a Tríplice Hélice Atuando no Monitoramento da Qualidade de Combustíveis
}

\author{
Innovations Developed in Universities - the Triple Helix Acting on Fuel \\ Quality Monitoring
}

\author{
Sthefania Fernandes Silva ${ }^{1}$ \\ Lenise Souza Cardoso de Andrade ${ }^{1}$ \\ Alysson Ferreira da Silva ${ }^{1}$ \\ Carlos Alexandre Camargo de Abreu ${ }^{1}$ \\ ${ }^{1}$ Universidade Federal do Rio Grande do Norte, Natal, RN, Brasil
}

\begin{abstract}
Resumo
Devido a Agência Nacional do Petróleo, Gás Natural e Biocombustíveis (ANP) demandar métodos mais eficazes nas análises de conformidade dos combustíveis, têm surgido pesquisas nessa área. Diante desse cenário, o presente artigo discute o papel dessas pesquisas, realizadas por universidades, como um meio perspicaz de atingir tal demanda. Em particular, a investigação é centrada no aperfeiçoamento dos métodos de monitoramento da qualidade de combustíveis no Brasil. A análise fundamenta-se em pesquisa exploratória qualitativa, alicerçada no levantamento dos níveis de não conformidade da qualidade de combustíveis publicados pela ANP. Partindo do conceito "tríplice hélice" e da interação entre governo-universidade-empresa, discute-se o efeito de leis de incentivo à inovação e casos de sucessos no transbordamento da produção científica para o mercado. A análise dos dados evidencia que a parceria público-privada aliada com políticas públicas relacionadas à inovação reduzem os níveis de não conformidade de gasolina, etanol e óleo diesel.
\end{abstract}

Palavras-chave: Inovação. Métodos de análise de combustível. Tríplice Hélice.

\begin{abstract}
Due to the Agência Nacional do Petróleo, Gás Natural e Biocombustíveis (ANP) demanding more effective methods in fuel compliance analysis, research has appeared in this area. Against the foregoing, the present article discusses the role of these researches, carried out by universities, as an insightful means of achieving such a demand. In particular, the research is focused on improving the methods of monitoring the quality of fuels in Brazil. The analysis is based on qualitative exploratory research, based on the survey of the levels of non-conformity of fuel quality published by ANP. Starting from the "triple helix" concept and the interaction between government-university-enterprise, is discussed the effect of laws to encourage innovation and success stories in the overflow of scientific production to the market. Data analysis shows that the public-private partnership combined with public policies related to innovation reduce the levels of non-compliance of gasoline, ethanol and diesel oil.
\end{abstract}

Keywords: Innovation. Fuel analysis methods. Triple helix.

Área tecnológica: Tecnologia. Propriedade Intelectual. Inovação Tecnológica. 


\section{Introdução}

A "lei do petróleo" além de quebrar o monopólio da Petrobras em 1997, criou um órgão regulador, a Agência Nacional do Petróleo, Gás Natural e Biocombustíveis (ANP), cuja responsabilidade é fiscalizar as atividades da indústria petrolífera. Um ano depois da implementação dessa lei, visto os números preocupantes de combustíveis não conformes em todo território brasileiro, foi criado o Programa de Monitoramento da Qualidade dos Combustíveis (PMQC) (ANP, 2017). Com o papel de fornecer indicadores de conformidade dos combustíveis às especificações estabelecidas pela ANP, o programa atua levantando dados da qualidade dos combustíveis líquidos comercializados no Brasil. Dessa forma, desde o início das suas atividades, o PMQC tem garantido uma severa mudança na qualidade dos combustíveis, em termos de amostras não conformes, por exemplo, a gasolina registrou $20 \%$ no ano de 1998 e alcançou a marca de 1,5\% em 2017 (ANP, 2018a).

Segundo o boletim de monitoramento da qualidade dos combustíveis da ANP do ano de 2017, em torno de 7 mil amostras eram coletadas por mês, e desse número, apenas 1,5\%,1,9\% e 3,3\% correspondem a amostras não conformes da gasolina; etanol hidratado e óleo diesel, respectivamente (ANP, 2018a). Para manter esse padrão, a ANP cada vez mais tem buscado métodos de análise mais rápidos, eficientes e sustentáveis, encontrando nas universidades e centros de pesquisa responsáveis pela análise de conformidade uma alternativa eficaz. Visto que, muitos deles além de analisar a qualidade dos combustíveis também detêm pesquisas voltadas para o desenvolvimento e aperfeiçoamento dos métodos analíticos utilizados.

Para o transbordamento de tais inovações das universidades ao mercado é necessária a intervenção do governo por meio de leis de incentivo à inovação como a Lei de Inovação, Lei do Bem e a mais recente Lei de Estímulo, o Novo Marco Legal da Ciência, Tecnologia e Inovação. Assim, a interação universidade-empresa é facilitada permitindo que as inovações desenvolvidas possam ser empregadas no mercado.

É dentro deste viés, que este artigo busca avaliar a importância das inovações criadas nas universidades federais, possuindo como estudo de caso as potencialidades mercadológicas de estudos relacionados a métodos analíticos de combustíveis que estão sendo aperfeiçoados $e$ desenvolvidos. Para isso, analisa-se três leis federais e duas estaduais de estímulo à inovação e da relação universidade-empresa. Também estuda-se casos de sucesso da relação universidade-empresa no Brasil e no mundo, evidenciando assim, a importância da tríplice hélice como elemento fundamental na criação de tecnologias na qual impactam na economia e sociedade.

\section{Referencial Teórico}

Apesar de o Brasil atrair atenção pelo seu tamanho e potencial econômico, ao longo dos anos vem perdendo prestígio no tocante à competitividade mundial. Em 2001, o País ocupava a $40^{\mathrm{a}}$ posição no ranking, entretanto, caiu para $60^{\mathrm{a}}$ em 2018 , segundo um estudo publicado pelo International Institute for Management Development (IMD) (FDC, 2018). Além disso, o fato de ocupar a $13^{a}$ posição na produção científica mundial contrasta com a resistência do País em estreitar a relação entre setor produtivo e universidades, seguindo com dificuldade em inovar (GARCIA, 2013). 
A fim de mudar esse quadro, os últimos governos direcionaram diversas regulamentações e iniciativas, como a Lei de Inovação, a Lei do Bem e a mais recente Lei de Estímulo à Inovação, o Novo Marco Legal da Ciência, Tecnologia e Inovação. A Lei de Inovação, criada em 2004, foi a lei pioneira do Brasil a abordar o relacionamento entre universidades e/ou instituições de pesquisa com empresas (NIEHUES, 2016). O objetivo da lei era a criação de ambientes adequados a parcerias entre institutos tecnológicos e universidades com empresas, estimular essas instituições no processo de inovação, e incentivar a inovação de empresas (PEREIRA; KRUGLIANSKAS, 2005).

Já a Lei do Bem, criada em 2005, foi uma política tecnológica de estímulo à inovação que fez parte das ideias expansionistas do governo de ampliação do desenvolvimento científico e tecnológico do Brasil. Para isso, propunha a redução de impostos nas empresas, nacionais e multinacionais, como mecanismo de apoio fiscal para estimular a inovação tecnológica por meio da produção de projetos PD\&I (SANCHES; BARBALHO, 2017).

Em janeiro de 2016, foi promulgada a Lei 13.243, denominada Novo Marco Legal da Ciência, Tecnologia e Inovação. Distribuída em 18 artigos, seu texto discute estímulos ao desenvolvimento científico, à pesquisa, à capacitação científica e tecnológica e à inovação, alterando uma série de leis vigentes. Ainda com as diretrizes da Tríplice Hélice, o Novo Marco Legal apresenta mecanismos que permitem maior autonomia e flexibilidade na relação entre setor privado, universidade e Estado (NIEHUES, 2016).

O Decreto 9.283, que alterou a Lei de Inovação de 2004 e regulamentou o Novo Marco Legal de 2016, tem 86 artigos que buscam desburocratizar cenário de inovação no Brasil, dentre essas mudanças estão: a autorização para docentes exercerem atividades de pesquisa remunerada no setor privado; permissão para que equipes de empresas utilizem laboratórios das universidades para fins de pesquisa; garantia da propriedade intelectual das empresas envolvidas em projetos sobre os resultados das pesquisas (ABGI GROUP, 2018).

Além dessas leis, programas recentes de governos estaduais buscam mudar tal cenário por meio de políticas de incentivo à inovação no meio acadêmico. Um exemplo disso é o "Programa Bahia de Inovação", criado em 2003, pela Fundação de Amparo à Pesquisa do Estado da Bahia (FAPESB). Esse programa visava ao desenvolvimento de projetos, com apoio da esfera federal, que possam fomentar as atividades inovadoras dentro das áreas prioritárias do Estado. Pretendendo assim, a promoção da inovação e do empreendedorismo, estimulando a cooperação entre as empresas, instituições de ensino superior, centros de pesquisa, organizações governamentais e o próprio governo (BAHIA, 2007 apud GUERRA; GOMES; CHENG, 2011, p. 9).

Outro exemplo é a Lei Paulista de Inovação criada em 2008, que de acordo com a Secretaria de Desenvolvimento do Estado, propõe estimular instituições (universidades, institutos de pesquisas e centros de conhecimento), empresas, pesquisadores públicos e inventores a participar do processo de inovação tecnológica. Tais envolvimentos objetivando a intensificação da integração dos centros de conhecimento aos setores de produção, por meio de incentivos diretos como autorização para utilização da infraestrutura de pesquisa existente, comercialização de patentes, licenças, apoio financeiro e até mesmo participação do estado em sociedades de propósito específico (GUERRA; GOMES; CHENG, 2011).

Sabendo da existência dessas leis e tendo em vista que as universidades são consideradas elementos-chave para o desenvolvimento econômico, as instituições de ensino e pesquisa assumem papel relevante na formação, criação e transferência do conhecimento (GUBIANI, 
2011). Nesse contexto, D'Avila et al. (ETZKOWITZ, 2003 apud D'AVILA et al., 2017) afirma que o mecanismo fundamental, a inovação e ao crescimento econômico, é a interação entre universidade-indústria-governo, já que o modelo permite o desenvolvimento regional com base no conhecimento. Além disso, essas interações permitem às empresas aquisição de maior competitividade, por meio de produtos mais densos em conhecimento (FACCIN et. al., 2012 apud D'AVILA et al., 2017).

$\mathrm{O}$ arranjo organizacional que engloba a interação entre universidade-governo-empresas é chamado tríplice hélice. Essa tese é alicerçada principalmente em a universidade assumir o papel equivalente da indústria e governo, como geradora de novas indústrias e empresas (ETZKOWITZ; ZHOU, 2017).

\section{Metodologia}

A abordagem utilizada para análise da problemática foi a pesquisa exploratória qualitativa, na qual foi alicerçada em dados bibliográficos, a partir do levantamento de referências teóricas publicadas por meios escritos e eletrônicos; como relatório de análise de competitividade, artigos científicos voltados para os estudos da tríplice hélice e da relação universidade-empresa; consulta a leis e decretos de estímulo à inovação e à Revista Pesquisa FAPESP. Além disso, coletou-se dados dos boletins mensais do PMQC, criando um gráfico da trajetória temporal de não conformidade dos três principais combustíveis utilizados no Brasil.

Foi utilizado como método de análise a pesquisa bibliográfica, realizada entre março e agosto de 2018, com base nas edições anteriores do Boletim de Monitoramento da Qualidade dos Combustíveis (disponibilizados no site da ANP), dissertações de mestrado, monografia, estudo de caso e trabalhos de conclusão de cursos (TCCs). A pesquisa teve como objetivo obter os registros que dizem respeito aos índices de não conformidade e conformidade da gasolina, óleo diesel e etanol hidratado, respectivamente, no período de 2011 a 2017.

As taxas anuais utilizadas no gráfico foram geradas calculando-se a média dos índices de não conformidade mensais, que além de encontrados nas pesquisas também foram determinados por meio dos índices de conformidade de cada combustível. Depois do levantamento, os dados foram transferidos para o Microsoft Excel para a criação da imagem.

É por meio desses métodos que o trabalho discute a história do PMQC e seu desempenho na atualidade, destacando o papel das universidades na geração de novas tecnologias. Para consolidar a discussão, apresentaram-se casos de sucesso no transbordamento de inovações criadas em universidades no Brasil; assim como a relação tríplice hélice como agente propulsor do mercado de combustíveis e economia brasileira, a partir da interação universidade-governo-empresa.

\section{Resultados e Discussão}

O progresso tecnológico (evolução científico-tecnológica) dos métodos de análise de combustível 
Vista a necessidade de controlar as atividades das indústrias de petróleo, gás natural e biocombustíveis no Brasil, em 1997, foi criada a Lei n 9.478/1997 mais conhecida como a "Lei do Petróleo", que além de determinar o fim do monopólio da empresa Petróleo Brasileiro S.A. (PETROBRAS), estabeleceu a criação da ANP. A Agência desde então ficou responsável pela regulamentação, contratação e fiscalização dos procedimentos relacionados ao petróleo no Brasil (ANP, 2017).

Além disso, essa lei atribuiu à ANP o encargo de estimular a pesquisa e a adoção de novas tecnologias para o setor, ou seja, os contratos celebrados entre a Agência e as empresas petrolíferas para exploração, desenvolvimento e produção de petróleo e gás natural dispõem, desde o início, de cláusulas de Pesquisa, Desenvolvimento e Inovação (PD\&I) que estabelecem a obrigação de realização de despesas qualificadas como PD\&I pelas empresas petrolíferas. A cláusula de PD\&I estabelece a aplicação de percentual da receita bruta da produção, segundo condições específicas de cada modalidade de contrato (ANP, 2018b).

Nos contratos de concessão, a PD\&I é obrigatória para campos de alta produtividade ou rentabilidade e equivale a $1 \%$ da receita bruta da produção de petróleo, gás natural e outros hidrocarbonetos. Para o contrato da $1^{\text {a }}$ Rodada de Partilha da Produção e o contrato da cessão onerosa, a PD\&I é obrigatória para qualquer volume de produção, sendo equivalente a $1 \%$ e $0,5 \%$, respectivamente, da receita bruta. Para os contratos da $2^{\mathrm{a}}$ e $3^{\mathrm{a}}$ Rodadas de Partilha da Produção, a obrigação de PD\&I equivale a $1 \%$ da receita bruta, conforme critérios específicos associados à profundidade batimétrica e aos procedimentos para recuperação do custo em óleo. Os valores gerados são investidos em projetos de PD\&I que podem ser executados pela própria empresa petrolífera, por empresas brasileiras ou por instituições credenciadas de todo o País (ANP, 2018b).

Um ano depois da criação da ANP, no fim de 1998, foi criado o PMQC com o papel de levantar dados de qualidade dos combustíveis líquidos comercializados no Brasil. Além disso, o Programa colabora na redução dos índices de não conformidade dos principais combustíveis consumidos em todo território nacional (ANP, 2017).

Segundo Lima (2012), antes do PMQC, o Centro de Pesquisas e Análises Tecnológicas (Cepat, hoje chamado de CPT20) realizava o acompanhamento da qualidade dos combustíveis com base em amostras coletadas pela Fiscalização do Departamento Nacional de Combustíveis (DNC), que, por muitas vezes, demoravam a chegar ao laboratório para análise. Ainda, segundo o autor, diversas visitas técnicas foram realizadas em várias universidades públicas, com o objetivo de criar um mecanismo ágil e eficiente capaz de levantar dados sobre a conformidade dos combustíveis comercializados em todo o território nacional.

No primeiro semestre de 1997, de acordo com Lima (2012), foi assinado um contrato entre o antigo DNC, a Delegacia do Ministério de Minas e Energia no estado de Santa Catarina (DMME/SC), e com o Instituto de Pesquisas Tecnológicas de Blumenau (IPTB-Furb), assegurando que o IPTB-Furb deveria realizar a coleta e análise das amostras de combustíveis no município de Blumenau, além de realizar ensaios em amostras coletadas pela fiscalização do DNC. Os resultados iniciais, segundo Lima (2012), reforçaram a ideia da criação de um programa de monitoramento em nível nacional como uma ferramenta efetiva para assegurar a qualidade dos combustíveis. Meses depois, com a extinção do DNC e a criação da ANP, o contrato com o IPTB-Furb foi extinto e repassada a responsabilidade a ANP em outubro de 1998, para coleta e análise de amostras de combustíveis no estado de Santa Catarina (LIMA, 2012). 
Os primeiros anos do PMQC mostraram que o programa, embora ainda sem alcance nacional, era capaz de produzir expressiva evolução na qualidade dos combustíveis. Visto que, no ano inicial da sua atuação, os dados fornecidos pelas 1.560 amostras coletadas indicavam que a não conformidade da gasolina chegava a $20 \%$ dependendo da região considerada. Contudo, dois anos depois as 24.362 amostras coletadas mostraram que esse percentual já havia sido reduzido para cerca de $12 \%$, índice ainda alto, mas inferior ao registrado no início do programa (LIMA, 2012).

A Figura 1 mostra os dados levantados pelo PMQC, desde o ano 2000 até 2010, expressando a redução nos índices de não conformidade.

Figura 1 - Histórico dos índices de não conformidade na qualidade de combustíveis no Brasil de 2000 a 2010

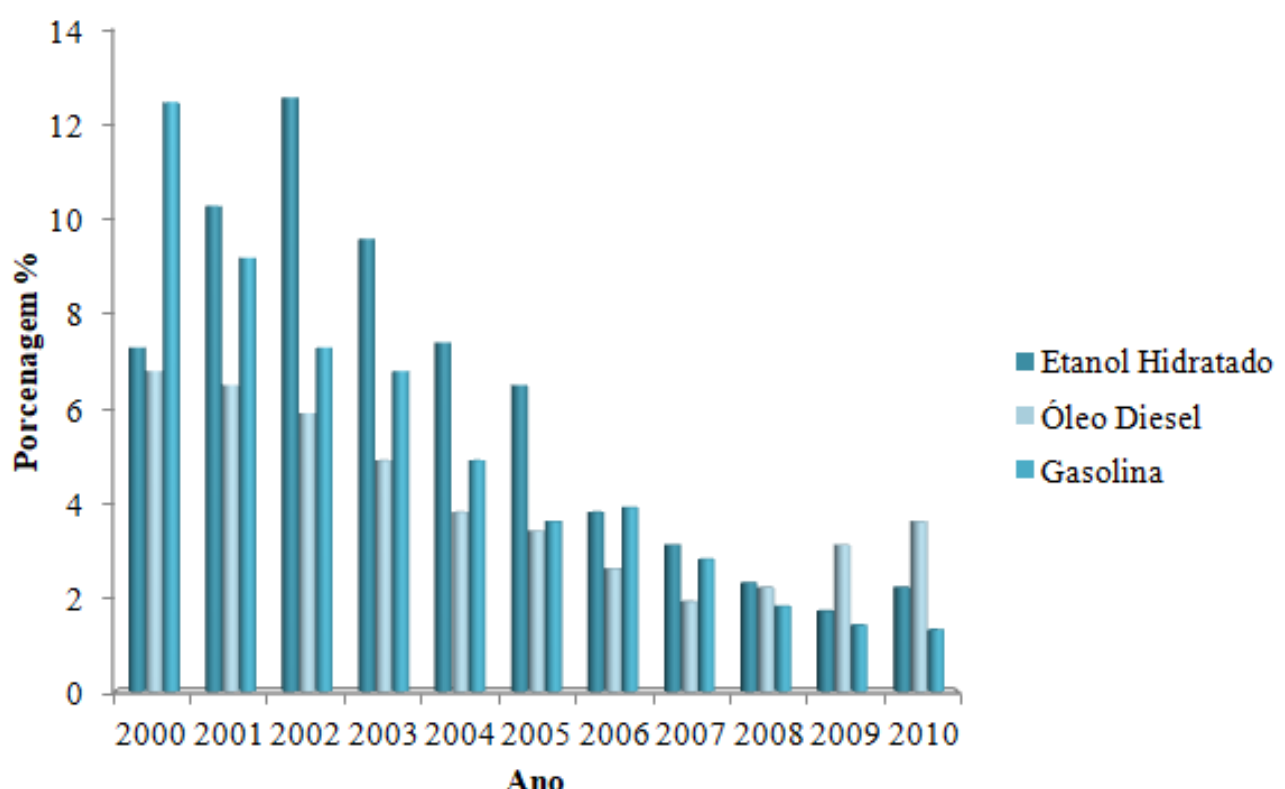

Fonte: Adaptado de Lima (2012)

A Figura 1 evidencia que, depois do início do PMQC, houve uma significativa redução na porcentagem de não conformidades dos três principais combustíveis utilizados no Brasil ao longo de 10 anos. O etanol com 12,6\% apresenta o maior percentual de adulteração registrado em 2002. Naquele ano, a principal causa de não conformidade, segundo Lima (2012), correspondia à massa específica/teor alcoólico, na qual a alteração, conhecida popularmente como "álcool molhado", consiste na adulteração do etanol por excesso de água. No caso da gasolina, também houve uma queda significativa desses índices no decorrer dos anos, registrando-se em 2010 o menor índice de 1,3\% de amostras não conformes - cerca de nove vezes menor do que o encontrado em 2000 (12,5\% de amostras não conformes).

Já o óleo diesel, obteve o índice de amostras em desconformidade com os parâmetros estabelecidos na legislação vigente no ano de 2010 de 3,6\%, valor duas vezes menor que o índice observado no ano de 2001 (6,5\% de amostras não conformes). Apesar de em 2007 ter sido registrado o menor índice de não conformidade (1,9\%), depois desse ano, os índices de não conformidade voltaram a crescer, fato atribuído principalmente à introdução em 2008 da 
adição de biodiesel no óleo diesel. Desconsiderando isso, os índices de 2009 e 2010 obtiveram variação normal como observado em outros períodos (LIMA, 2012).

Dados mais recentes mostram que essas taxas de inconformidade estão diminuindo ainda mais com o aumento da atuação do PMQC no Brasil no decorrer dos anos, como mostra a Figura 2.

Figura 2 - Histórico dos índices de não conformidade na qualidade de combustíveis no Brasil de 2011 a 2017

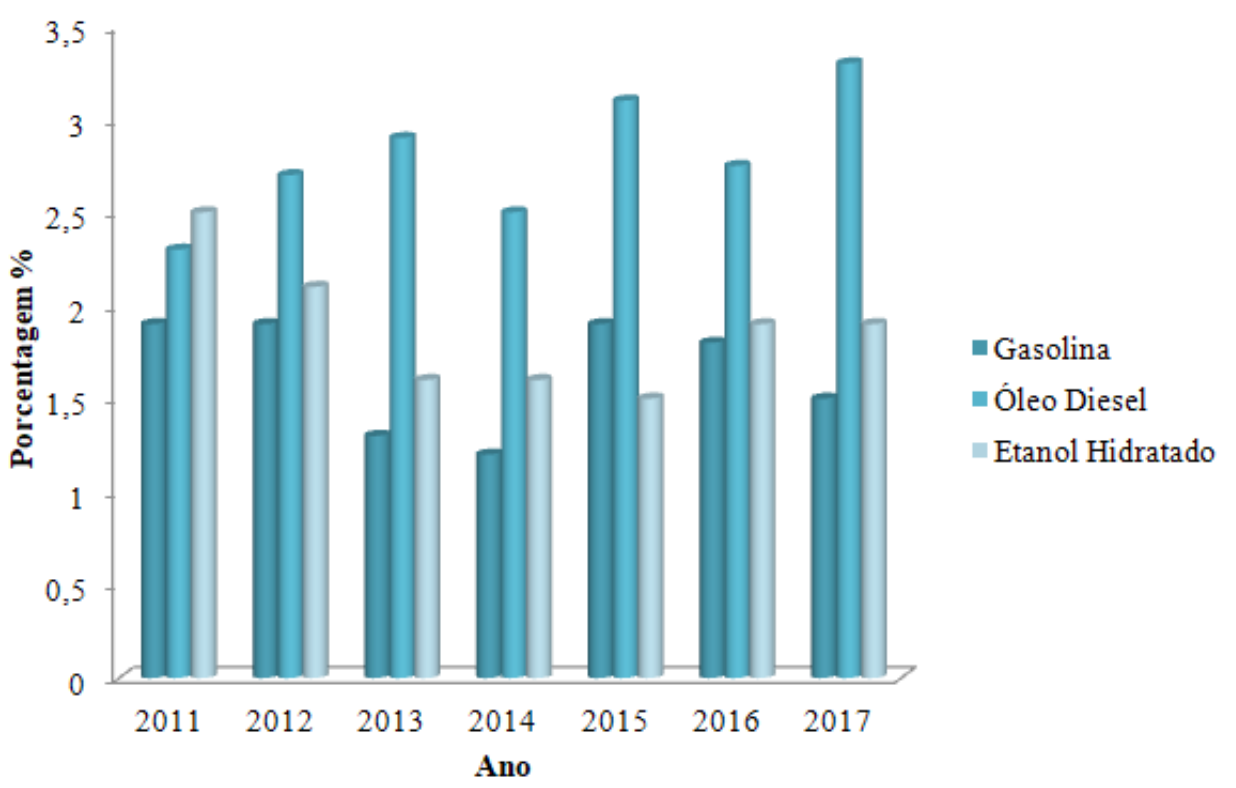

Fonte: Adaptado de ANP (2018)

A Figura 2 mostra dados mais recentes dos índices de não conformidade dos combustíveis brasileiros reafirmando o impacto positivo da atuação desse Programa no Brasil.

Dessa forma, o PMQC vem atuando no Brasil, contando para sua execução, com uma rede de 22 instituições e centros de pesquisas em todo o País (MENDES, 2012). Atualmente, essas análises funcionam em quatro etapas: primeiramente ocorre a coleta diária de amostras de combustíveis nos postos de todo o Brasil. Em seguida, as amostras são enviadas para análise em um laboratório próprio da ANP ou contratado (instituições de ensino ou pesquisa contempladas dos certames licitatórios). Depois disso, há o encaminhamento dos resultados das análises à ANP para a avaliação e consolidação dos dados gerais da qualidade dos combustíveis no País. Só então há a ampla divulgação dos resultados consolidados por meio do Boletim Mensal da Qualidade dos Combustíveis Líquidos Automotivos Brasileiros, e a comunicação das não conformidades ao setor de fiscalização da Agência e aos órgãos de controle (LIMA, 2012).

Ao receber os resultados das amostras coletadas a ANP analisa e verifica, principalmente dentre os resultados de amostras não conformes, a presença de algum dado incorreto ou incoerente em relação aos demais resultados da amostra. Havendo necessidade, é solicitada à contratada a retificação do resultado ou a reanálise da amostra. Depois da análise dos dados pela Superintendência de Biocombustíveis e Qualidade de Produtos (SBQ), é elaborada e encaminhada à Superintendência de Fiscalização da ANP uma planilha contendo os dados das amostras que apresentaram não conformidades. Consta-se dados do tipo de combustível 
coletado, data, CNPJ, razão social, endereço e bandeira do agente econômico em que foi constatada a não conformidade. Essas informações são agrupadas por regiões e encaminhados aos respectivos escritórios regionais da fiscalização da ANP e aos Ministérios Públicos Estaduais que solicitam informações de não conformidades (LIMA, 2012).

\subsection{O Papel das Universidades na Geração de Novas Tecnologias}

O conhecimento e a inovação são fundamentais para o sucesso competitivo das organizações e, por isso, faz-se necessário conhecer as possibilidades de criação de novos conhecimentos e a geração de inovações tecnológicas, como as produzidas por parcerias tecnológicas entre empresas e universidades (MELO, 2012).

Nesse cenário, a necessidade que o governo e/ou empresas possuem do auxílio das universidades ou institutos no processo de inovação não é recente, tendo se originado na descoberta por países desenvolvidos, quando objetivavam defender seus territórios; entendeu-se que a maneira mais inteligente e rápida de gerar novas tecnologias era por meio das pesquisas realizadas nas universidades e centros de pesquisa (GIRARDI et al., 2014).

A transferência de conhecimento entre universidades e empresas é atualmente um tema relevante de atenção e pesquisa, tanto em estudos econômicos quanto de gestão. E também, está conquistando um tópico de destaque na agenda de políticas de ciência e tecnologia, tanto de países desenvolvidos quanto em desenvolvimento (MELO, 2012).

Não por coincidência diversas empresas aderiram a essa ideia Por exemplo, a Boeing que utiliza da Northwestern University e da Washington University para gerar suas pesquisas inovadoras. O mesmo acontece com a empresa Hewlett-Packard (HP), que busca por inovações no meio acadêmico e por isso, mantém laboratórios avançados nas universidades de Oregon na Califórnia, e em outras no Vale do Silício. A Standard Oil semelhantemente às anteriores, patrocina laboratórios nas Universidades de Chicago e de Virginia. O Google e a Microsoft também atuam da mesma maneira. Todas essas empresas são cientes que o investimento nas universidades tem se mostrado melhor e mais econômico do que o investimento em departamentos de Pesquisa e Desenvolvimento (GIRARDI et al., 2014).

Já no Brasil, pode-se dizer que o debate sobre a relação universidade-empresa é relativamente recente. Foi estimulado principalmente na década de 1980, quando o País enfrentou uma profunda crise fiscal, e os investimentos para o setor de C\&T tornaram-se escassos, fato que ainda perdura na atualidade. Os orçamentos dos órgãos públicos foram substancialmente reduzidos, e em muitos casos até abaixo da sobrevivência institucional, forçando diversas instituições de ensino e pesquisa a se aproximarem do setor produtivo (BALDINI; BORGONHONI, 2007).

Além disso, para Costa (2007 apud MELO, 2012), no caso brasileiro a cooperação universidade-empresa desponta como meio de reduzir o atraso tecnológico da indústria nacional. "Essa a cooperação se constitui em um meio de reunir potencialidades e oportunidades, reduzindo as dificuldades para alcançar o desenvolvimento tecnológico tão necessário às empresas brasileiras." (PORTO, 2000 apud MELO, 2012, p. 31). 


\subsection{Caso de Sucesso: fotômetro analisador de combustível desenvolvido na Universidade Estadual de Campinas (Unicamp)}

As inovações concebidas em universidades estão começando a ingressar com mais frequência no mercado brasileiro. Essa é uma das formas que as empresas encontraram de agregar tecnologia em produtos e processos gerando o crescente aumento de licenciamentos de propriedade intelectual de universidades e a transformação desse conhecimento em produtos inovadores (ERENO, 2013).

Um exemplo de tecnologia promissora que transbordou para o mercado no final de 2012 foi o fotômetro analisador de combustível desenvolvido no Instituto de Química da Universidade Estadual de Campinas (Unicamp). Tal produto foi licenciado para a Tech Chrom, empresa gestada na Incubadora de Empresas de Base Tecnológica da Universidade (Incamp) (ERENO, 2013).

De acordo com Arruda (2012), o diretor da Tech Chrom afirmou que essa tecnologia trabalha na região do infravermelho próximo e foi desenvolvida para detectar a adulteração em combustíveis líquidos pela determinação do teor de água no álcool etílico hidratado carburante (AEHC) e do teor de álcool etílico combustível (AEAC) na gasolina. Além de não gerar resíduo, o fotômetro apresenta resultado direto no visor do aparelho em menos de um minuto. Além disso, o teste obtém resultado instantâneo, então, é possível identificar adulterações no produto a tempo de coletar uma amostra de contraprova para análise completa em laboratório especializado, explica o diretor da empresa (ARRUDA, 2012).

Enquanto os testes para avaliação de adulteração de combustíveis nos postos necessitam de várias etapas e de pessoas treinadas para examinar as informações, o fotômetro apresenta o resultado diretamente no visor do aparelho em pouco tempo. Além disso, o teste tradicional de gasolina necessita de 50 mililitros ( $\mathrm{ml}$ ) do combustível e o de etanol de 1 litro. Já o aparelho com o fotômetro funciona com apenas $5 \mathrm{ml}$ de combustível inserido em um recipiente apropriado. "Só é preciso informar se a análise é de etanol ou gasolina", diz Ismael Pereira Chagas, que desenvolveu o protótipo do analisador de combustível durante o seu doutorado e, atualmente, trabalha como pesquisador na empresa (ERENO, 2013).

O aparelho chamado Xerloq, é capaz de armazenar na memória os resultados de até 98 análises. "Também foi desenvolvido um software para imprimir o resultado da análise do combustível para o cliente do posto.", diz Chagas. Com o projeto do Pesquisa Inovativa em Pequenas Empresas (Pipe), a empresa conseguiu reduzir o preço de venda de $\mathrm{R} \$ 6.800,00$ para $\mathrm{R} \$ 4.950,00$. Até agora foram vendidos mais de 50 aparelhos para postos revendedores e distribuidoras de combustível. "Mas há um mercado em potencial para explorar, porque existem cerca de 39 mil postos espalhados pelo Brasil.", afirmou Matos (ERENO, 2013).

Dessa forma, pode-se apontar que o fotômetro analisador de combustível trouxe vantagens aos proprietários de postos de combustíveis e aos consumidores. Isso se dá, segundo Matos, por oferecer a realização da análise de dois combustíveis em apenas um aparelho de forma rápida, segura e sem geração de resíduo, demonstrando ao cliente rapidamente a qualidade do combustível (ARRUDA, 2012), além de ser essencial para o cumprimento dos objetivos do PMQC. 


\subsection{O Transbordamento de Inovações das Universidades como Ferramenta para Aprimorar a Atuação do PMQC e o seu Impacto no Mercado e Economia Brasileira}

A atuação do PMQC é restrita a 22 instituições que abrangem quase todo o território nacional trazendo diversos benefícios. Primeiro, contribui para o controle dos agentes econômicos do mercado sujeitos ao objeto do Programa (revendedores e distribuidores), segundo por fornecer dados importantes para a fiscalização da própria Agência - como pode ser observado nas Figuras 1 e 2 - subsidiando-a quanto aos possíveis agentes que devem ser vistoriados. Além disso, defende os interesses dos consumidores, principalmente aqueles que estão no varejo quanto à qualidade dos combustíveis.

A análise, atualmente, é realizada em quatro etapas. Da coleta de dados até a divulgação dos resultados é necessário não só tempo, como também ambientes e equipamentos propícios para seu cumprimento. Para garantir uma maior rapidez associada à eficiência e agilidade, a ANP busca meios de facilitar a verificação de conformidade. Dessa forma, o órgão governamental tem recorrido às universidades responsáveis pela realização das análises, investindo em pesquisas e estudos que propõe o desenvolvimento e/ou aperfeiçoamento desses métodos analíticos.

Esse auxílio requisitado pelo órgão governamental, na busca por inovações nas universidades não é recente e advém da solução encontrada pelos países desenvolvidos, que no passado enfrentaram dificuldade em inovar, para a problemática de gerar novas tecnologias. Essa solução fundamentou-se no modelo da tríplice hélice, na qual a relação entre universidade-governo-empresas está bem definida e completa. Exemplos bem sucedidos dessa relação podem ser encontrados nos ecossistemas de inovação dos Estados Unidos, como na Northwestern University e Washington University com seu vínculo com o Boeing; assim como a empresa HP também busca por inovações no meio acadêmico mantendo laboratórios avançados nas universidades de Oregon na Califórnia, e outras empresas mundialmente conhecidas como o Google e a Microsoft também atuam da mesma maneira.

No Brasil, apesar de tardia, essa relação está começando a ganhar espaço. Visto que, nos últimos anos a criação de leis como a Lei do Bem; Lei de Inovação e o Novo Marco Legal, que visam à criação de um ambiente adequado a parcerias entre institutos e universidades com empresas e incentivo dessas instituições no processo de inovação. Em outras palavras, são leis de estímulo à tríplice hélice.

A implementação de políticas estaduais objetivando estimular a geração de inovações nas universidades mostrou-se eficiente, exemplo disso é o Programa Bahia de Inovação e a Lei Paulista de Inovação. O Programa Bahia de Inovação tem o intuito de desenvolver projetos, com apoio da esfera federal, visando à aplicação de ideias inovadoras das nas áreas prioritárias do próprio estado, com vistas à promoção da inovação e ao empreendedorismo, estimulando a cooperação entre as empresas, instituições de ensino superior, centros de pesquisa, organizações governamentais e do próprio governo. Já a Lei Paulista de Inovação objetiva estimular instituições de pesquisa, empresas, pesquisadores públicos e inventores a participar do processo de inovação tecnológica para intensificar a integração dos centros de conhecimento com os setores de produção. A adoção dessas medidas não só facilita a realização de pesquisas científicas nas universidades, como também o transbordamento dos estudos. 
Além disso, o Novo Marco Legal da Ciência, Tecnologia e Inovação que em 2018 foi implementado a partir do Decreto 9.283, é o mais recente ordenamento jurídico na qual a inovação é incentivada. As normas contidas nele buscam simplificar a burocracia e estimular a interação entre pesquisadores, universidades e instituições de pesquisas, empresas e governo. Dessa forma, essa lei é fundamental para consolidação da tríplice hélice no Brasil.

Nesse contexto, uma tecnologia brasileira envolvendo métodos analíticos que conseguiu escoar para o mercado brasileiro foi o fotômetro analisador de combustível. Desenvolvido no Instituto de Química da Unicamp e licenciado para a Tech Chrom, o aparelho oferece diversas vantagens no que diz respeito à praticidade, eficiência, rapidez e sustentabilidade. Visto que não gera resíduo, apresenta resultado direto no visor do aparelho em menos de um minuto, utiliza um volume menor na amostra, é capaz de armazenar na memória os resultados de mais de 90 análises, dentre outras vantagens como vantajoso custo-benefício e fácil manuseio. Apesar de, atualmente, o objetivo da empresa e dos pesquisadores ser a venda desse aparelho para postos revendedores de combustível, essa tecnologia tem total capacidade de ser utilizada pelo PMQC para realizar os objetivos da ANP.

Casos como esse, evidenciam a importância do investimento nas universidades para a realização dessas pesquisas, além de corroborar o impacto que elas podem trazer para a sociedade e a economia como um todo. Diante disso, observa-se que a relação tríplice hélice e as políticas que incentivam a inovação são elementos importantes que podem tornar o Brasil mais competitivo, além de mantê-lo em uma posição favorável no ranking de produção científica.

Sendo assim, os projetos que buscam criar uma tecnologia que atinja o objetivo da ANP de aperfeiçoar os métodos analíticos de combustível ou desenvolver novos, impactam o mercado de combustíveis e a economia brasileira. Visto que, a tecnologia irá facilitar a identificação de adulterações mantendo o combustível brasileiro na qualidade requerida, como no caso do fotômetro analisador de combustível desenvolvido na Unicamp.

Reforça-se, então, a importância das universidades na geração de inovações, evidenciando a necessidade de ampliação do transbordamento das tecnologias desenvolvidas a partir de pesquisas científicas em universidade e institutos científicos, já que essa contribuição mostra-se tão benéfica para a sociedade.

\section{Considerações Finais}

Sabe-se que ainda há dificuldade das empresas brasileiras incorporarem produtos inovadores no mercado. No entanto, medidas de estímulo atuais, como a Lei de Inovação, a Lei do Bem e o Novo Marco Legal, além das políticas estaduais como a Programa Bahia de Inovação e a Lei Paulista de Inovação estão sendo empregadas para aumentar a parceria público-privada $e$ o investimento empresarial na área de inovações nas universidades.

A relação universidade-empresa tem se mostrado bastante benéfica em vários países, como visto nos exemplos das universidades dos Estados Unidos. No Brasil, apesar de resultados desse tipo de investimento serem iniciais, o fotômetro analisador de combustível desenvolvido pela Unicamp em 2012, comprova a eficácia de tais investimentos.

Tais exemplos enfatizam o quão importante é o transbordamento de pesquisas científicas das universidades para o mercado, e consequentemente para a economia. Evidenciando que 
também é possível para o Brasil transbordar e impactar o mercado com as tecnologias desenvolvidas nas universidades e institutos tecnológicos.

Logo, com ampliação dessa relação pesquisas que visam ao aprimoramento e/ou desenvolvimento de metodologias de análise, essenciais para fazer a caracterização dos combustíveis de maneira eficiente e prática, poderão entrar no mercado brasileiro evitando adulterações e garantindo a qualidade da gasolina, etanol hidratado e óleo diesel.

\section{Referências}

ABGI GROUP. As contribuições do Decreto no $\mathbf{9 . 2 8 3 / 1 8}$ para o ecossistema de inovação. 2018. Disponível em: <http://brasil.abgi-group.com/radar-inovacao/as-contribuicoes-do-decreto-no9-283-18-para-as-leis-de-incentivo-inovacao/> . Acesso em: 25 jul. 2018.

AGÊNCIA NACIONAL DO PETRÓLEO, GÁS NATURAL E BIOCOMBUSTÍVEIS (ANP). Boletim de Monitoramento da Qualidade dos Combustíveis. Edições Anteriores. 2018a. Disponível em: $<$ http://www.anp.gov.br/publicacoes/boletins-anp/2388-pmqc-edicoes-anteriores > . Acesso em: 25 jul. 2018.

Investimentos em PD\&I. 2018b. Disponível em: <http:/www.anp.gov.br/pesquisadesenvolvimento-e-inovacao/investimentos-em-p-d-i > . Acesso em: 23 jul. 2018.

Lei do petróleo completa 20 anos. 2017. Disponível em: <http://www.anp.gov.br/ noticias/3928-lei-do-petroleo-completa-20-anos > . Acesso em: 3 abr. 2018.

ARRUDA, A. Empresa graduada na Incamp lança tecnologia no InovaCampinas. Portal Unicamp. 2012. Disponível em: <http:/www.unicamp.br/unicamp/noticias/2012/06/13/empresa-graduada-naincamp-lanca-tecnologia-no-inovacampinas > . Acesso em: 12 jun. 2018.

BALDINI, J. P.; BORGONHONI, P. As relações universidade-empresa no Brasil: surgimento e tipologias. Caderno de Administração, Maringá, v. 15, n. 2, p. 29-38, jul./dez. 2007.

D'AVILA, Jones Costa et al. A tríplice hélice como fator de desenvolvimento regional sob a ótica de especialistas. International CONGRESSO INTERNACIONAL DE CONHECIMENTO E INOVAÇÃO (CIKI), VII. out. 2017. Proceedings... Florianópolis: EGC/UFSC, 2017. Disponível em: <http:// proceeding.ciki.ufsc.br/index.php/ciki/article/view/179>. Acesso em: 4 mai. 2018.

ERENO, D. Conhecimento no mercado, empresas recorrem a universidades para lançar produtos mais competitivos. Revista Pesquisa FAPESP, São Paulo, ed. 209, jul. 2013.

ETZKOWITZ, H.; ZHOU, C. Hélice Tríplice: inovação e empreendedorismo universidade-indústriagoverno. Estudos Avançados, São Paulo, v. 31, n. 90, maio/ago. 2017. Disponível em: < http:// www.scielo.br/scielo.php?script=sci_arttext\&pid=S0103-40142017000200023 >. Acesso em: 10 jun. 2018.

GARCIA, M. Os obstáculos para a inovação no Brasil. GGN O jornal de todos os Brasis, [online]. 3 abr. 2013. Disponível em: < https://jornalggn.com.br/blog/os-obstaculos-para-a-inovacao-nobrasil >. Acesso em: 28 maio 2018.

GIRARDI, B. A. et al. O desenvolvimento de inovações através da interação universidadeindústria e os resultados positivos dessa parceria. In: SIMPÓSIO DE EXCELÊNCIA EM GESTÃO E TECNOLOGIA (SEGET), XI., [S.1.: s.n], 2014. 
GUBIANI, J. Modelo para diagnosticar a influência do capital intelectual no potencial de inovação nas universidades. 2011. 194 f. Tese (Doutorado em Engenharia e Gestão do Conhecimento) - Programa de Pós-Graduação em Engenharia e Gestão do Conhecimento. Universidade Federal de Santa Catarina, Florianópolis, 2011.

GUERRA, P. V.; GOMES, D. T.; CHENG, L. C. Universidade Empreendedora: o caso do Programa de Incentivo à Inovação. 2011. In: ENCONTRO DA ANPAD, XXXV - ENANPAD. 4 a 7 dez. Rio de Janeiro, 2011.

INTERNATIONAL INSTITUTE FOR MANAGEMENT DEVELOPMENT E FUNDAÇÃO DOM CABRAL (FDC). Relatório de análise de competitividade 2018: sem as reformas necessárias, Brasil se mantém entre os países menos competitivos do mundo. Nova Lima: International Institute For Management Development, 2018. Disponível em: <https://www.fdc.org.br/conhecimento-site/ nucleos-de-pesquisa-site/Materiais/Relat\%C3\%B3rio_Analise_Competitividade_2018_FDC_IMD. pdf > . Acesso: 28 maio 2018.

LIMA, Alexandre de Souza. O Programa de Monitoramento da Qualidade dos Combustíveis (PMQC). 5. ed. Rio de Janeiro: Centro de Documentação e Informação da ANP, 2012.

MELO, D. R. A. Relação universidade-empresa no Brasil: o papel da academia em redes de coinvenção. 2012. 204 f. Tese (Doutorado em Administração) - Programa de Pós-Graduação em Administração da Escola de Administração. Universidade Federal da Bahia, Salvador, 2012.

MENDES, G. Detecção de adulterações em gasolina e previsão de parâmetros FísicoQuímicos a partir de curvas de destilação associadas a ferramentas quimiométricas. 2012. 131 f. Tese (Doutorado em Ciências - Química) - Universidade Federal de Minas Gerais, Belo Horizonte, 2012.

NIEHUES, B. F. Novo Marco Legal da Ciência, Tecnologia e Inovação: a Lei no $13.243 / 2016$ e a proteção do interesse público na interação público-privado. 2016. 72 f. Trabalho de Conclusão de Curso (Graduação em Direito) - Departamento de Direito. Universidade Federal de Santa Catarina, Florianópolis, 2016.

PEREIRA, J.; KRUGLIANSKAS, I. Gestão de inovação: a lei de inovação tecnológica como ferramenta de apoio às políticas industrial e tecnológica do Brasil. 2005. Disponível em: <http:// www.scielo.br/scielo.php?script=sci_arttext\&pid=S1676-56482005000200003 >. Acesso em: 30 maio 2018.

SANCHES, E. A.; BARBALHO, S. C. M. Lei do Bem no Brasil: evolução histórica, efeitos e o futuro. 2016. Disponível em: <http://propesq.ufsc.br/files/2017/05/Artigo_ Evolu\%C3\%A7\%C3\%A3o-Efeitos-e-Futuro-da-Lei-do-Bem_rev0.pdf > . Acesso em: 30 maio 2018.

\section{Sobre os autores}

\section{Sthefania Fernandes Silva}

E-mail: sthefaniafernandes03@gmail.com

Graduada (Bacharelado) em Ciências e Tecnologia, pela Universidade Federal do Rio Grande do Norte (UFRN). Endereço profissional: Campus Universitário Lagoa Nova, Escola de Ciências e Tecnologia, Sala 54 - Natal, RN. CEP: 59078-970. 


\section{Lenise Souza Cardoso de Andrade}

E-mail: lenise.andrade@live.com

Técnica em Petróleo e Gás, pelo Instituto Federal do Rio Grande do Norte (IFRN) Natal-Central; e graduanda (Bacharelado) em Ciências e Tecnologia, pela Universidade Federal do Rio Grande do Norte (UFRN).

Endereço profissional: Campus Universitário Lagoa Nova, Escola de Ciências e Tecnologia, Sala 54 - Natal, RN. CEP: 59078-970.

\section{Alysson Ferreira da Silva}

E-mail: alyssonfds@hotmail.com

Graduado em Ciências e Tecnologia (bacharelado), pela Universidade Federal do Rio Grande do Norte (UFRN).

Endereço profissional: Campus Universitário Lagoa Nova, Escola de Ciências e Tecnologia, Sala 54 - Natal, RN. CEP: 59078-970.

\section{Carlos Alexandre Camargo de Abreu}

E-mail: calexandreabreu@ect.ufrn.br

Doutor em Ciências e Engenharia de Petróleo, pela Universidade Estadual de Campinas (Unicamp);

mestre em Engenharia de Produção, pela Universidade Federal de Santa Catarina (UFSC); e graduado em Ciências Econômicas, pela Universidade do Estado do Rio de Janeiro (UFRJ).

Endereço profissional: Campus Universitário Lagoa Nova, Escola de Ciências e Tecnologia, Sala 54 - Natal, RN. CEP: 59078-970. 